\title{
Preparando pessoas com deficiência para o mercado de trabalho de Tecnologia da Informação e Comunicação
}

\author{
Michel Fornaciali ${ }^{1}$, Lucimara de Almeida ${ }^{1}$, Luis Rogério Gomes de Almeida ${ }^{1}$ \\ ${ }^{1}$ Instituto de Pesquisas Eldorado \\ Av. Alan Turing, 275 - Cidade Universitária - Barão Geraldo \\ Campinas - SP - Brasil - CEP 13083-898 \\ \{michel.fornaciali, lucimara.almeida, luis.rogerio\}eldorado.org.br
}

\begin{abstract}
Surveys reveal that, despite of the difficulties, employers believe that people with disabilities - PWD - can assume any position in companies, nevertheless the low qualification of these people is the major obstacle for hiring. This paper shows the experience of Eldorado Research Institute in training PWD in topics of Information and Communications Technology. Differently from other initiatives focused only in basic computer teaching, the project presented here prepares PWD to act as software developers and testers able to face this job market so competitive and demanding in terms of professional qualifications. This paper presents the project's conception and conduction processes, showing the achievements during its seven years of existence.
\end{abstract}

Resumo. Pesquisas indicam que apesar das dificuldades, os empregadores acreditam que pessoas com deficiência - PcD - podem assumir diversos cargos nas empresas, no entanto a baixa qualificação desse público é o maior impedimento para a contratação. Esse artigo relata a experiência do Instituto de Pesquisas Eldorado na capacitação de PcD em temas de tecnologia. Diferentemente de outras iniciativas focadas apenas em informática básica, o Eldorado prepara pessoas para atuarem como desenvolvedores e testadores de software aptos para esse mercado de trabalho tão exigente em termos de qualificação profissional. $O$ artigo mostra os processos de concepção e condução do projeto, apresentando os resultados obtidos nos seus sete anos de existência.

\section{Introdução}

O mercado de Tecnologia da Informação e Comunicação (TIC) está em constante crescimento e demanda profissionais com os mais diversos perfis técnicos. Várias empresas do ramo, por um lado incentivadas pela Lei de Cotas e por outro pela necessidade de obter mão-de-obra qualificada vêm contratando profissionais com deficiência para preencher as vagas de trabalho. Por conta da necessidade de mão-de-obra qualificada, o processo de contratação precisa ser acompanhado pela formação profissional, imprescindível para a realização satisfatória das atividades do setor. Suprir tal demanda dessas empresas é extremamente desafiador e abre espaço para diversas iniciativas de inclusão e capacitação.

Sabe-se que a tecnologia é um instrumento poderoso no ensino de pessoas com deficiência $(\mathrm{PcD})$. A informática tem sido utilizada em diversos contextos para auxiliar a aprendizagem e potencializar os resultados da capacitação [Fernandes et al. 2012] e [Bastos et al. 2010]. 
Além de ser um instrumento de apoio ao ensino, a informática também pode ser encarada como o próprio tema de capacitação das PcD. Iniciativas dessa forma são encontradas no país e no mundo, mas em menor quantidade [da Silva et al. 2013] e [Barbosa et al. 2013]. Tais treinamentos visam preparar a PcD para interagir com um computador ou aparelho móvel (smartphone ou tablet) enquanto usuários, ou seja, preparam o indivíduo para utilizar os recursos fornecidos pela tecnologia assim como um usuário sem deficiência o faria.

O que pouco tem sido discutido é sobre a capacitação de $\mathrm{PcD}$ para atuarem como protagonistas da informática, ou seja, prepará-los para construírem sistemas computacionais para uso próprio ou geral. Iniciativas de capacitação de PcD para torná-las profissionais aptos a preencherem vagas em empresas de informática não são encontradas com facilidade.

No que tange à capacitação de profissionais de informática, o Instituto de Pesquisas Eldorado ${ }^{1}$, proponente deste projeto, é responsável pela criação de projetos de capacitação gratuitos para os participantes em temas ligados à TIC, como Informática Básica, Metodologias de Desenvolvimento de Software, Linguagens de Programação, Circuitos Integrados Analógicos e Digitais e Aceitabilidade de Montagens Eletrônicas, destinados a qualquer público. Desde 1999 já foram capacitados 12.000 alunos em projetos educacionais em parceria com empresas e universidades de todo o país. Os projetos abrangem, principalmente, treinamentos presenciais, mas também são oferecidos cursos à distância com alunos de diversos estados brasileiros. Desde 2009, mais de 25.000 alunos tiveram acesso a cursos a distância e 1.500 desses tiveram acesso a cursos com metodologia baseada em atividades síncronas e assíncronas.

Aproveitando a experiência adquirida em projetos de capacitação realizados anteriormente, bem como a oportunidade de preparação de PcD para o mercado de informática, a instituição decidiu criar em 2007 o projeto "Oficina do Futuro PcD - A competência faz a diferença" ${ }^{2}$, com o objetivo de capacitar PcD em tópicos de TIC para suprir a constante demanda do mercado. Neste artigo será apresentada a expertise da instituição neste segmento e os principais resultados alcançados nos seus sete anos de atuação. $O$ artigo apresenta o processo desafiador de montagem de uma turma tão específica quanto essa, relata as metodologias de ensino e compila as principais dificuldades e resultados da iniciativa.

O artigo está organizado como segue. A Seção 2 indica as principais motivações que levaram à criação do projeto. A Seção 3 discorre sobre o plano de trabalho central bem como as premissas e restrições. A Seção 4 relata detalhes específicos da divulgação, aplicação dos treinamentos, métodos de avaliação e a finalização das turmas. A Seção 5 sumariza os principais resultados obtidos nos sete anos de atuação do projeto. Por sua vez, a Seção 6 finaliza o artigo com as considerações finais e os próximos passos.

\section{Contextualização}

Segundo a Organização das Nações Unidas (ONU), cerca de $15 \%$ da população mundial possui algum tipo de deficiência [UN Enable], e cerca de $80 \%$ dessa população

\footnotetext{
${ }^{1}$ Conheça o Instituto de Pesquisas Eldorado: http://www9.eldorado.org.br/

${ }^{2}$ Conheça o projeto Oficina do Futuro PcD: http://www.oficinadofuturopcd.com.br/
} 
vive em países em desenvolvimento [ONU BR]. Especificamente no Brasil, de acordo com o Censo Demográfico de 2010, 23,9\% da população declarou portar algum tipo de deficiência ou incapacidade (visual, auditiva, motora e mental ou intelectual) [IBGE - Instituto Brasileiro de Geografia e Estatística 2010]. A Figura 1-a mostra a distribuição dessa população por região do país.

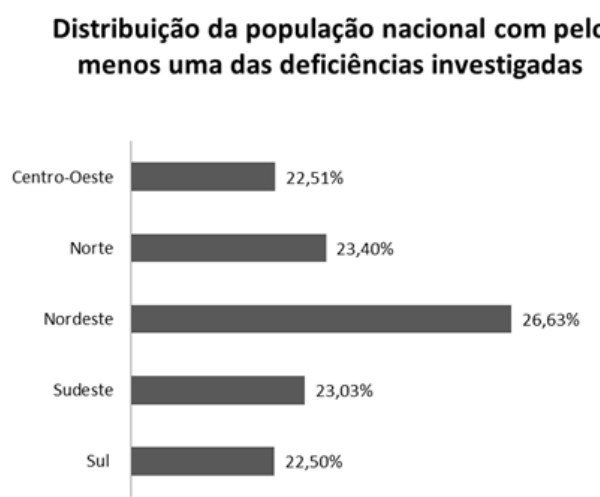

(a)

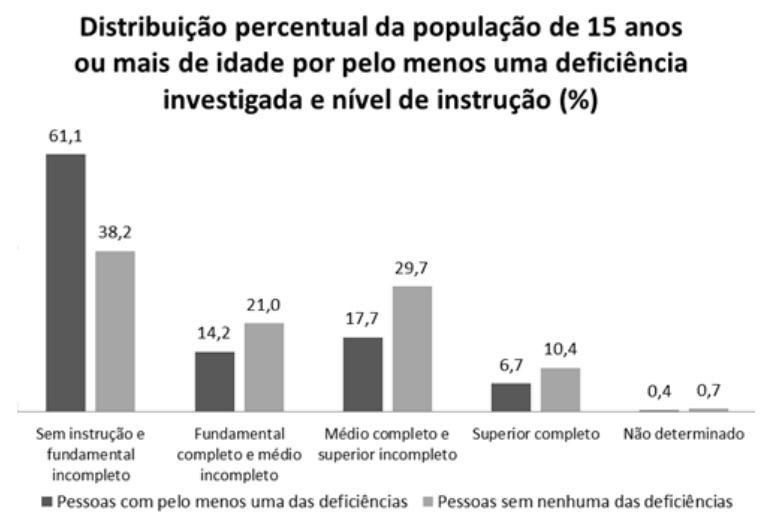

(b)

Figura 1. Dados do Censo Demográfico de 2010. A Figura (a) revela a distribuição da população nacional com pelo menos uma das deficiências investigadas (visual, auditiva, motora e mental ou intelectual). A Figura (b) compara a distribuição percentual da escolaridade das pessoas com pelo menos uma das deficiências investigadas com a de pessoas sem deficiência. Imagens reproduzidas ou adaptadas de [Censo 2010].

Para impulsionar a participação dessa parcela da população no mercado de trabalho, foi promulgada em 1991 a lei número 8.213 conhecida como Lei de Cotas, a qual dispõe sobre os Planos de Benefícios da Previdência Social e dá outras providências para os brasileiros deficientes. O Artigo 93 da Lei de Cotas diz que "a empresa com 100 (cem) ou mais empregados está obrigada a preencher de $2 \%$ (dois por cento) a $5 \%$ (cinco por cento) dos seus cargos com beneficiários reabilitados ou pessoas portadoras de deficiência". Caso a empresa não cumpra a Lei, ela está sujeita a sanções financeiras e demais penalidades legais perante os órgãos trabalhistas.

No entanto, existem algumas barreiras para o cumprimento da Lei. O estudo de [MANZINI and TANAKA 2005] aponta que os empregadores acreditam que as PcD possuem condições de exercer as atividades corriqueiras de boa parte dos postos de trabalho, mas apontam dificuldades em função da baixa escolaridade, de condições físicas inadequadas das empresas, da mobilidade urbana precária até o trabalho e também dos programas insuficientes de treinamento profissional.

Outro estudo realizado em 2007 por uma empresa parceira do Instituto de Pesquisas Eldorado apontou que a escolaridade da maior parte das PcD contratadas está fortemente concentrada no Ensino Fundamental e Médio. Este resultado está coerente com o cenário nacional, como pode ser constatado na Figura 1-b, a qual revela a escolaridade da população brasileira com deficiência em contraste com a população sem as deficiências investigadas de acordo com o Censo de 2010. Um dos maiores motivos para essa falta de capacitação está na motivação de tais pessoas, as quais acabam desistindo dos estudos devido a dificuldades diversas, como mobilidade urbana, acessibilidade de instituições de 
ensino e até mesmo superproteção familiar. Por outro lado, a mesma pesquisa de 2007 apontou que $85 \%$ das empresas admitiram não possuir um programa de treinamento para $\mathrm{PcD}$, esperando que eles venham capacitados do mercado.

Tratando diretamente do mercado de Tecnologia da Informação (TI), a pesquisa de 2007 revelou que o número de PcD contratadas era praticamente nulo. No entanto, 72\% das empresas pesquisadas afirmaram pretender contratar PcD para atuar principalmente nas áreas de suporte técnico.

Dado esse cenário, o Instituto de Pesquisas Eldorado propôs, em 2007, a capacitação de PcD através da criação de um projeto inovador para tal, denominado "Oficina do Futuro PcD - A competência faz a diferença". Os treinamentos do Oficina do Futuro PcD são oferecidos gratuitamente e focam em temas de TIC, que são áreas de atuação do Eldorado. Hoje, os moldes do projeto foram seguidos por outras iniciativas, como, por exemplo, o "Programa Qualificar para Incluir" criado em 2008 pelo CPqD e o "Programa de Inclusão" da CI\&T criado em 2014.

\section{Metodologia}

Esta seção contempla a metodologia de trabalho do projeto Oficina do Futuro PcD. Ela descreve em alto nível todas as etapas para construção e condução de cada turma, bem como discorre sobre as premissas e restrições do projeto.

Em linhas gerais, cada turma é preparada para atender aos requisitos das empresas parceiras do projeto que visam capacitar PcD para a inclusão social e profissional dessas pessoas no mercado de trabalho e possível contratação ao final do projeto. Assim, as atividades de capacitação são alinhadas com as demandas técnicas e comportamentais do parceiro e de outros possíveis contratantes, já que acredita-se que empresas do mesmo setor tenham demandas semelhantes. Esse alinhamento permite que a equipe do projeto direcione seus esforços para buscar alunos participantes com o perfil esperado para ingresso nas turmas. O projeto contempla capacitação presencial e conta com infraestrutura adaptada para receber os participantes, bem como instrutores capacitados para o melhor atendimento ao público com deficiência, o que inclui a presença de monitores em sala de aula para melhor acompanhar o andamento das turmas. O corpo de instrutores e monitores é preparado em palestras de sensibilização com o objetivo de informá-los sobre o conceito da deficiência, trabalhar mitos e preconceitos e dicas de relacionamento com as PcD. Todo o material didático é adaptado para o público alvo e existe um treinamento de nivelamento dos participantes. Além das atividades de capacitação técnica as PcD participantes recebem treinamentos comportamentais ministrados por profissionais de Recursos Humanos. Tais atividades complementares visam o desenvolvimento social e organizacional do grupo, na construção de uma carreira profissional. No caso de treinamentos para PcD cognitiva também é feito um acompanhamento psicológico.

\subsection{Plano de trabalho central}

Conforme dito anteriormente, todas as turmas do projeto Oficina do Futuro PcD são realizadas em parceria com empresas que desejam contratar PcD para compor seu quadro de colaboradores. Cada turma possui suas peculiaridades e requisitos específicos de plano de aulas e proposta de trabalho, mas todas seguem a mesma metodologia de formação e condução. O fluxo de ações está ilustrado na Figura 2. 


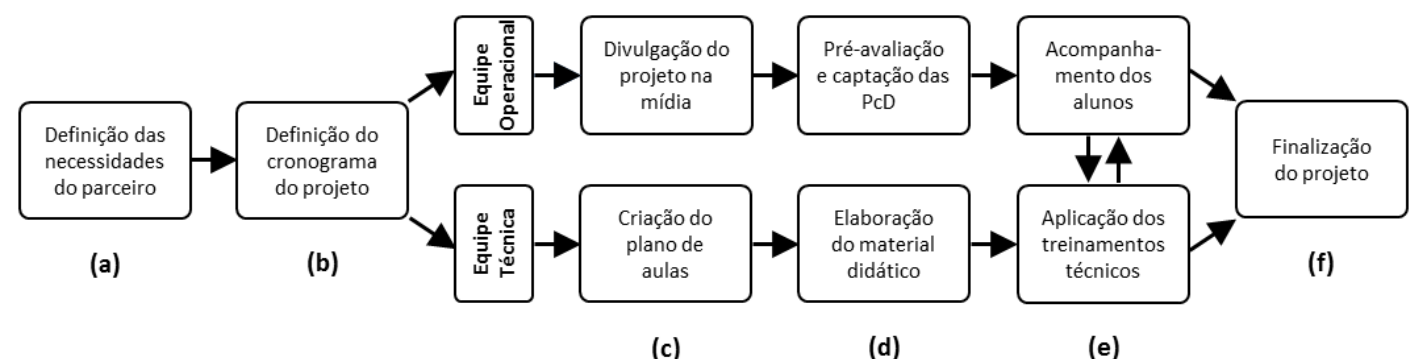

Figura 2. Fluxograma de uma instância padrão do projeto Oficina do Futuro PcD. Toda turma é financiada por uma empresa parceira, geralmente interessada em contratar as PcD ao final da capacitação. O fluxo padrão do projeto é: (a) o Instituto Eldorado se reúne com a empresa parceira e realiza-se o alinhamento do escopo do projeto. Após esta etapa, inicia-se a fase (b) na qual o Eldorado elabora um cronograma do projeto que é validado pelo parceiro. Nesta fase o projeto é dividido em 2 vertentes: equipe técnica, focada em assuntos técnicos (como aplicação das aulas), e equipe operacional, focada em assuntos de recursos humanos, operações de acompanhamento e logística (como a captação e acompanhamento dos participantes). Na fase (c), a equipe operacional realiza a divulgação do projeto na mídia, bem como treina os professores para melhor atender às necessidades do público alvo. Nessa mesma fase, a vertente técnica define um plano de aulas alinhado com os requisitos do parceiro e prepara um cronograma de ensino. Na fase seguinte (d), a vertente operacional cuida da seleção dos participantes de acordo com os requisitos do parceiro, enquanto a equipe técnica prepara os professores e cria materiais didáticos. Na próxima fase (e), inicia-se o período de aplicação dos módulos do projeto e a equipe operacional acompanha o rendimento dos alunos. Por fim, na fase (f) ocorre a conclusão dos módulos e a finalização daquela turma.

A Figura 2 ilustra, de forma resumida, as principais ações do projeto Oficina do Futuro PcD. Ao iniciar cada turma do projeto, o Instituto Eldorado se reúne com a empresa parceira para alinhamento do escopo do projeto, como, por exemplo, o número de participantes desejados, local de aplicação dos treinamentos, perfil desejado e prérequisitos para os participantes, temas técnicos a serem tratados em sala, infraestrutura, entre outros. Após esta etapa, elabora-se um cronograma do projeto definindo as principais ações, marcos de entregas e divisão de tarefas (Figura 2-b). Nesta fase ocorre a divisão do projeto em duas vertentes: uma equipe operacional (como divulgação do projeto e captação dos participantes) e outra focada em assuntos técnico-pedagógicos (como a preparação de planos de aula, criação de materiais didáticos e aplicação dos módulos). Na fase seguinte (Figura 2-c), a equipe operacional divulga o projeto nos meios específicos (detalhados na próxima seção) e oferece treinamentos para os instrutores e monitores, de modo a prepará-los para melhor atender os alunos. Enquanto isto, a equipe técnica cuida da criação do plano de aulas alinhado com os requisitos do parceiro. Na etapa posterior, (Figura 2-d), a vertente operacional cuida da seleção dos participantes de acordo com os requisitos do parceiro, enquanto os responsáveis técnicos preparam os instrutores e criam materiais didáticos. Esse processo também será detalhado nas próximas seções. Na penúltima etapa do processo (Figura 2-e), inicia-se o período de aplicação dos módulos técnicos e a equipe operacional acompanha o rendimento dos alunos. Nesta fase ocorre uma intensa troca de experiências entre a equipe operacional e os instrutores 
para consolidação de feedbacks e replanejamentos, se necessário. Por fim, na última fase (Figura 2-f), ocorre a conclusão dos módulos. O organizador do projeto informa o status final da capacitação bem como a avaliação de cada participante para a empresa parceira, a qual pode aproveitar a turma formada para preencher vagas de trabalho. Vale ressaltar, que além do conhecimento medido através das avaliações somativas aplicadas ao final de cada módulo, os instrutores também identificam atitudes e habilidades dos participantes como trabalho em equipe, liderança, responsabilidade, organização, iniciativa, proatividade e autonomia.

\subsection{Premissas e restrições}

Em termos de premissas, sabe-se através de turmas aplicadas anteriormente, que em locais atendidos por transporte público adequado e com infraestrutura preparada para tal, há uma menor evasão dos participantes. As turmas são oferecidas de acordo com a deficiência dos alunos, ou seja, pode haver turmas específicas para determinadas deficiências com o intuito de oferecer atendimento customizado ao aluno. Um exemplo clássico é a turma composta por deficientes auditivos, a qual é totalmente acompanhada por um intérprete de Língua Brasileira de Sinais (LIBRAS). Como os participantes não necessariamente possuem formação prévia formal na área, é comum cada turma ser heterogênea, composta por pessoas com experiência prévia em TIC ao lado de pessoas que estão ingressando na área ou até mesmo que não tiveram uma experiência profissional anterior. Acredita-se que o desafio dessa heterogeneidade possa gerar benefícios aos alunos, pois aqueles que se destacam costumam auxiliar os outros colegas, num intenso e proveitoso intercâmbio de conhecimento, exercendo inclusive, habilidades de trabalho em equipe e proatividade. Por fim, há a preocupação em selecionar pessoas psicologicamente preparadas para o mercado de trabalho para compor as turmas. Esse fator é de extrema importância uma vez que participantes que tomaram a decisão de levar a vida em frente independentemente da sua condição física ou das necessidades especiais são menos propensos às frustrações do mercado de trabalho e são mais suscetíveis à realização profissional.

Em relação às restrições, o projeto não é oferecido em locais que não tenham acessibilidade, que ofereçam dificuldades para a locomoção e comunicação dos participantes, o que abrange tanto a adequação do local físico quanto a preparação na recepção, a qual deve estar pronta para auxiliar a PcD na sua chegada e saída das aulas. O projeto também exige comprometimento dos participantes em todo o período de capacitação, ou seja, espera-se que o participante ingressante permaneça no curso até sua finalização. Essa ressalva é importante dada a constante concorrência com o próprio mercado: a PcD que conclui os módulos básicos do projeto passa a ser assediada por diversas empresas, e se contratada prematuramente, abandona as atividades de capacitação deixando de concluir os módulos avançados. Essa evasão gera lacunas nas turmas que não podem ser preenchidas por uma nova pessoa. Um exemplo típico é a carreira de desenvolvedor Android, na qual alguns participantes abandonam o curso por terem sido contratados por empresas do mercado logo após a finalização dos módulos básicos de Introdução à Informática e Programação Java. Por fim, ao propor a criação de uma turma com uma empresa parceira, é solicitado que ela, supostamente interessada na contratação dessas pessoas, esteja sempre presente durante o processo de seleção e capacitação dos participantes: isso demonstra a eles que não estão sem perspectivas de contratação e evita a evasão prematura para o mercado. 


\section{Condução do projeto}

Essa seção discorre com maiores detalhes as atividades pertinentes de cada macro-etapa do projeto, incluindo exemplos de situações vivenciadas e contemplando as lições aprendidas nestes sete anos de existência.

\subsection{Processo de divulgação e seleção dos alunos}

As turmas geralmente ocorrem em grandes centros urbanos. Portanto, a divulgação é feita massivamente na cidade que abrigará o curso e também em cidades próximas, se o deslocamento até o local das aulas for considerado aceitável. A divulgação ocorre majoritariamente pela mídia local, como jornais, rádios e divulgação via Organizações Não Governamentais (ONG) e entidades ligadas a pessoas com deficiência. É interessante notar que em turmas realizadas nas cidades do interior, o rádio continua sendo um excelente instrumento de disseminação do projeto.

A seleção é feita mediante análise do perfil do candidato versus o perfil requerido pelo projeto, análise de currículo e entrevistas presenciais, essas acompanhadas por profissionais de Recursos Humanos da empresa parceira. Qualquer PcD pode participar da seleção, independentemente da sua deficiência. Nas entrevistas o candidato recebe informações sobre as empresas responsáveis pela realização do projeto e os objetivos da capacitação.

\subsection{Aplicação dos treinamentos}

Conforme mencionado anteriormente, o projeto Oficina do Futuro PcD foca na capacitação de pessoas em temas de TIC. Portanto, as atividades de capacitação são divididas em módulos de acordo com a natureza dos temas tratados. Geralmente, o módulo inicial, Introdução à informática, abrange noções de Hardware e Software, utilização de ferramentas Office, Organização de Computadores e Internet. O módulo seguinte, Introdução à Programação, contempla temas específicos do mundo do desenvolvimento, com aulas de Lógica de Programação, Orientação a Objetos, Java, .NET/C\# e Android. Por fim, o módulo de Temas Especiais trata de outros assuntos ligados à Computação, mas que não necessariamente, dizem respeito à programação. Destacam-se nesse módulo os treinamentos de Engenharia de Software, SCRUM, Testes de Software, Bancos de Dados e também Treinamentos Comportamentais ministrados por profissionais de Recursos Humanos.

A carga horária de cada módulo não é uniforme, uma vez que temas mais complexos como desenvolvimento de software exigem maior dedicação. Ao contrário de [Carvalho 2013], todos os cursos são presenciais para melhorar o engajamento dos participantes. Acredita-se que ministrar aulas em um projeto com essa natureza não deva envolver aulas remotas. Apesar de as aulas remotas sanarem o problema do deslocamento, elas agravam os problemas de comunicação e entendimento, diminuindo as relações professoraluno e aluno-aluno, que são mais fortalecidas num ambiente presencial. Tais relações são importantes para o processo de aprendizagem pois fornecem subsídios para atuação imediata do instrutor, assim que são detectadas necessidades de intervenção.

\subsection{Método de avaliação}

Todas as turmas do projeto contam com três processos distintos de avaliação: a avaliação dos participantes, dos instrutores e do projeto em si. Para avaliar os participantes, aplicam- 
se avaliações somativas, com provas e trabalhos teóricos e práticos durante e/ou ao final de cada módulo. Também usa-se a percepção do instrutor sobre o comportamento do participante em sala (proatividade, interesse, curiosidade, trabalho em equipe, responsabilidade, organização, entre outros). No final de cada módulo, aplica-se uma pesquisa de satisfação anônima para que os participantes avaliem a atuação do instrutor em termos de competência técnica, transmissão do conhecimento, uso de recursos adequados e utilização do tempo. Por sua vez, o conteúdo do módulo é avaliado quanto a sua ementa, carga horária, metodologia de ensino e introdução de novos conceitos. Além disso, essa pesquisa contempla a avaliação dos recursos utilizados, como qualidade da instalação física, horário das atividades, pontualidade, e também o aproveitamento pelos participantes, quanto a aplicabilidade do aprendizado e atendimento das expectativas.

\subsection{Finalização}

Quando uma turma do projeto Oficina do Futuro PcD chega ao fim, as avaliações de desempenho dos participantes são consolidadas e aqueles com aproveitamento (nota final maior ou igual a 7 e presença maior ou igual a $75 \%$ das aulas) recebem um certificado de conclusão. Ocorre uma reunião com a empresa parceira que apoia a iniciativa e passa-se o status de cada participante, para que ela possa utilizar tais informações para contratações derivadas do projeto.

Uma vez terminado o ciclo de avaliações, inicia-se o processo de realimentação do projeto Oficina do Futuro PcD, utilizando as opiniões expressadas anonimamente pelos participantes para aprimorar ainda mais o formato do projeto e a dinâmica das atividades. Os feedbacks são transmitidos aos instrutores, todas as considerações a respeito do curso são analisadas e, quando possível, incorporadas em turmas futuras, no que vem a ser um ciclo de lições aprendidas.

\section{Resultados}

O projeto Oficina do Futuro PcD tem apresentado bons resultados desde sua implantação em 2007. A cada turma realizada confirma-se o sucesso da abordagem proposta para capacitação de PcD em temas de TIC. Com um total de 24 turmas concluídas em parceria com 5 empresas, o quadro de alunos está exibido na Tabela 1. Em ampla expansão nacional, o projeto conta, até o momento, com 402 participantes da região Sudeste, 49 participantes da região Sul e 10 participantes da região Centro-Oeste.

Na Tabela 1 vemos que apesar de o projeto ter sido criado em 2007, a primeira turma concluída ocorreu no início de 2008. A tabela releva a porcentagem de concluintes de cada turma. Nota-se que apesar do projeto ser desenhado para melhor atender ao público alvo, a taxa de conclusão global com aproveitamento ainda é de 73,6\%, indicando a ocorrência de desistências ao longo das atividades. Uma parte expressiva dessas desistências decorre da concorrência com o mercado de trabalho, bem como dificuldades de mobilidade urbana, problemas pessoais, financeiros e sociais, e também devido à falta de experiência ou inclinação dos participantes na carreira de TIC.

No entanto, não há dúvidas de que o projeto Oficina do Futuro PcD contribui para o país, uma vez que cria o laço entre empresas e alunos, contribuindo para a inclusão social e possibilitando que as $\mathrm{PcD}$ assumam seus papéis no mercado de trabalho. Do ponto de vista das empresas, o projeto identifica as necessidades do mercado e as leva 
Tabela 1. Distribuição total de participantes do Oficina do Futuro PcD. Consideram-se participantes todos os alunos que ingressaram na turma. São concluintes todos aqueles que chegaram ao final do projeto com aproveitamento.

\begin{tabular}{|c|c|c|c|}
\hline Ano & Participantes & Concluintes & $\%$ \\
\hline 2008 & 118 & 96 & 81,36 \\
\hline 2009 & 79 & 62 & 78,48 \\
\hline 2010 & 57 & 35 & 61,40 \\
\hline 2011 & 93 & 73 & 78,49 \\
\hline 2012 & 40 & 28 & 70,00 \\
\hline 2013 & 64 & 38 & 59,38 \\
\hline TOTAL: & $\mathbf{4 5 1}$ & $\mathbf{3 3 2}$ & $\mathbf{7 3 , 6 1}$ \\
\hline
\end{tabular}

para a sala de aula. Do ponto de vista dos alunos, o projeto os capacita para atuar no setor. Ao proporcionar uma capacitação gratuita que leva a PcD a ter acesso a vagas de emprego de forma mais igualitária, o projeto também é responsável pelo aumento da satisfação e realização pessoal dos participantes.

\section{Conclusão}

Esse artigo apresenta o projeto Oficina do Futuro PcD, proposto pelo Instituto de Pesquisas Eldorado, relatando a experiência do Eldorado na capacitação de $\mathrm{PcD}$ em temas de TIC. Ao contrário de outras iniciativas que utilizam a tecnologia apenas como apoio ao ensino, ou iniciativas de inclusão digital voltadas à informática básica, este projeto foca na preparação dos participantes para atuarem no mercado de trabalho de informática, desempenhando funções de alto grau de complexidade, como desenvolvimento ou teste de software.

Ao longo do artigo discutiu-se a metodologia de formação do projeto bem como detalhes da sua operação, culminando em excelentes resultados práticos. Os resultados apresentados demonstram a eficiência da abordagem o que justifica a manutenção do projeto por sete anos consecutivos, sempre em franca expansão.

A iniciativa pioneira no Brasil é de suma importância para o país pois identifica necessidades do mercado de trabalho de informática e as une com interesses das PcD que queiram trabalhar no setor. Dessa forma, cria-se uma oportunidade única na qual todos os envolvidos ganham: os participantes se capacitam tornando-se mais atrativos para o mercado, as empresas aproveitam a oferta de PcD capacitadas para completar seu quadro de funcionários e o projeto ganha visibilidade. Além dos benefícios profissionais, nota-se um reflexo positivo nas esferas afetiva e social dos participantes, os quais aumentam sua auto-estima e sentem-se participantes ativos da sociedade.

Por fim, apesar dos excelentes resultados alcançados até o momento, ainda existe espaço para complementação do projeto. Espera-se que em turmas futuras seja realizado o acompanhamento dos participantes após a capacitação, de modo a coletar níveis de empregabilidade derivados diretamente dessa iniciativa e verificar sua eficácia. Espera-se também que o projeto possa ocorrer em outras localidades, beneficiando empresas e PcD de outras regiões do país. 


\section{Agradecimentos}

Os autores, em nome do Departamento de Educação do Instituto de Pesquisas Eldorado, agradecem profundamente a todas as pessoas que tornam realidade o projeto Oficina do Futuro PcD, sobretudo os instrutores que participaram do projeto. Agradecimentos especiais a Dr. Arthur João Catto pela revisão e contribuições ao texto, a Raquel Cremasco Takaki pelos excelentes esclarecimentos sobre a Lei de Cotas, e a Maria Lúcia Legaspe e equipe pelo imenso apoio na divulgação do projeto. Esse artigo é fruto do trabalho de vocês.

\section{Referências}

Barbosa, A. F., Martins, R. d. O., and Santos, H. R. M. (2013). Uma experiência no ensino de informática para deficientes visuais no município de garanhuns-pe. In Anais do Workshop de Informática na Escola, volume 1.

Bastos, B. L., D Abreu, J., Borges, M., Ferreira, C., and Rizzieri, D. (2010). Implementação de maquete tátil sonora para pessoas com deficiência visual. In Anais do Workshop de Informática na Escola, volume 1, pages 1079-1086.

Carvalho, T. F. F. d. (2013). Ensino de informática básica a deficientes visuais em regime e-learning em cabo verde.

Censo 2010. Cartilha do Censo 2010 - Pessoas com Deficiência. http://goo.gl/TIZQsy. Acessado em: 17/07/2014.

da Silva, W. A., Junior, O. H., Freire, Â. A. C., and Valenzuela, G. M. (2013). Projeto incluir: inclusão digital para pessoas com deficiência. In Anais do Workshop de Informática na Escola, volume 1.

Fernandes, A. M. d. R., Costa, F. O. C., Lamha, A. P. S. F., and Moreira, D. S. (2012). Ensinando saúde bucal para deficientes visuais através de uma ferramenta web. In Anais do Workshop de Informática na Escola, volume 1.

IBGE - Instituto Brasileiro de Geografia e Estatística (2010). Censo demográfico: resultados preliminares. In XII Censo Demográfico.

MANZINI, E. J. and TANAKA, E. D. O. (2005). O que os empregadores pensam sobre o trabalho da pessoa com deficiência. Revista Brasileira de Educação Especial, pages 273-294.

ONU BR. A ONU e as pessoas com deficiência. http://www.onu.org.br/a-onu-em-acao/aonu-e-as-pessoas-com-deficiencia/. Acessado em: 17/07/2014.

UN Enable. Factsheet on Persons with Disabilities. http://www.un.org/disabilities/default.asp?id=18. Acessado em: 17/07/2014. 